\title{
O PRECONCEITO TECNOLÓGICO E O CONHECIMENTO INDÍGENA DA NATUREZA
}

\author{
Eduardo Carrara *
}

(1) s indios ainda hoje. passados quinhentos anos do descobrimento da América (1492), são alvo de muitos preconceitos. O mais forte delesé o preconceito tecnológico do Ocidente, o qual caracteriza os índios das Américas como "sociedades primitivas". Segundo interpretações de missionários, viajantes e precurssores do estudo antropológico, tais eram vistas como possuidoras de uma tecnologia incipiente (domínio rudimentar sobre a natureza), de hábitose costumes de povos não civilizados, isto é, "selvagens" e "bárbaros".

Tratarei sucintamente da origem científica deste preconceito específico e de como se deve lançar um novo olhar sobre as culturas indigenas. Uma vez que a "cultura material" indígena também é claborada através do pensamento e conhecimento que estes povos possuem da nature$\mathrm{za}$, aqueles devem ser bases de sustentação de tecnologias avançadas que lidam hoje com o meio ambiente e seu desenvolvimento.

$$
* * *
$$

Antropólogos da era vitoriana, como Frazer e Tylor, valiam-se da "cultura material" dos aborigenes para mostrar que existia uma ligação estreita entre 0 grau de desenvolvimento tecnológico e o nível de organização social. Isto é, quanto mais desenvolvida a tecnologia (metalurgia, agricultura, indústria, etc.), maior a complexidade e organização social humana e; quanto menor o desenvolvimento tecnológico (coleta, caça, pesca, etc.), menor o grau de organização e institucionalização da sociedade. Este raciocínio, denominado evolucionista, também era válido para as necessidades sociaisque provocavam novos desenvolvimen-

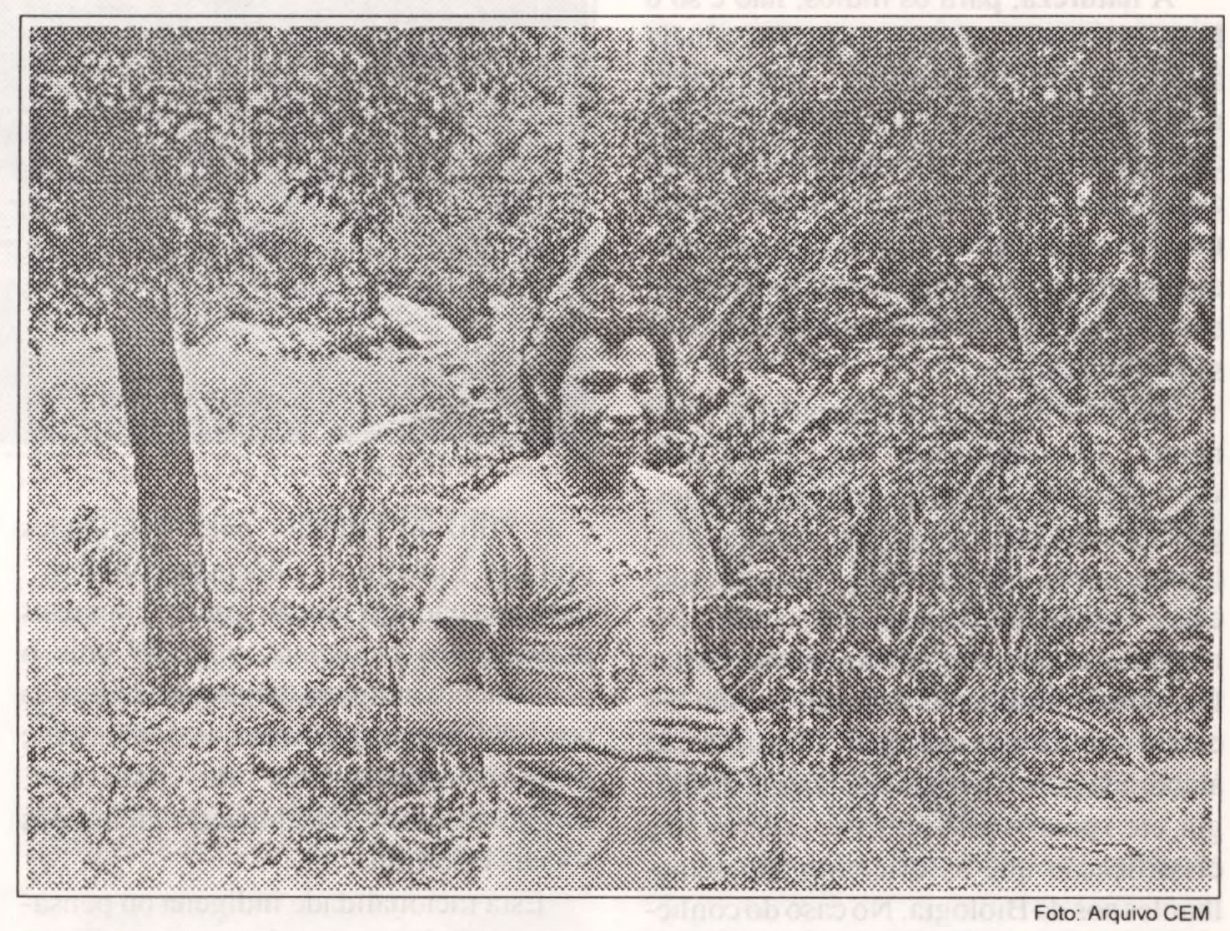

tos tecnológicos. ou seja, existiram evoluções sociais que provocaram demandas tecnológicas. Mas por que então as sociedades indígenas permaneceram no estado de "sclvageria" e "barbárie", como querem nos fazer acreditar os evolucionistas?

Podemos caracterizar a questão acima como um falso problcma pois as sociedades indigenas foram consideradas " primitivas", "selvagens" ou "bárbaras", a partir de uma perspectiva etnocêntrica. Comparadas material e socialmente com o Ocidente, eram classificadas como os primeiros estágios pelos quais passou a sociedade ocidental. Vistas sob um olhar etnocêntrico e evolucionista, tais sociedades não possuiam histórias próprias, mas participavam da história universal do gênero humano que culmina (segundo os evolucionistas da época) na civilização curopéia. O "homem civilizado", assim, nada mais é do que um produto de desenvolvimentos tecnológicos e sociais pelos quais passou a humanidade.

Ao contrário do que o senso comum e os evolucionistas da época pensavam, cada sociedade, seja qual for, tem sua história de transformações técnicase sociais (diferenciada, logicamente, das dos Ocidente), onde a tecnologia não determina pura $\mathrm{e}$ simplesmente a complexidade de uma organização social e nem tampouco o curso de sua transformação. A tecnologia é um produto histórico, ligado à relação das sociedades com o meio ambiente que as envolvem, ao modo de organização social, econômica e política de um povo.

Para irmos além dos preconceitos e etnocentrismos é preciso entender não o porque dos índios não terem alcançado o 
grau de conhecimento científico e tecnológico do Ocidente, mas como a ciência e a "tecnologia" (que não é aplicação direta da ciência) que podem ser traduzidas, a grosso modo, como relação prática $\mathrm{e}$ simbólica entre o homem e a natureza, são trabalhadas pelo pensamento indígena.

\section{A ciência do concreto indígena e a ciência ocidental}

A natureza, para os índios, não é só o lugar de onde retiram sua subsistência através da coleta, agricultura, caça e pesca; mas é também objeto de uma observação cuidadosa e atenta que nomeia, ordena e classifica as diversas espécies naturais do meio em que vivem. Enfim, consiste este conhecimento e aprendizado da natureza em uma das principais substâncias do pensamento indígena.

As classificações indígenas do meio natural são riquíssimas $\mathrm{em}$ termos para variedades de espécies, sub-subespécies, gênerose categorias mais abrangentes (abstratas), como, por exemplo, todas as espécies e variedades de aves conhecidas, denominadas por um único termo. Estas taxonomias indígenas da natureza são tão científicas como qualquer classificação alaborada pela Biologia (Botânica, Zoologia, etc.) pois os princípios de ordenação e classificação que as orientam são semelhantes aos da Biologia. No caso do conhecimento zoológico indigena (etnozoologia), seus critérios de classificação baseiam-se na morfologia e comportamentos específicos das espécies.

$\mathrm{A}$ observação indigena dos hábitos $\mathrm{e}$ comportamentos de animais é bem mais desenvolvida do que a elaborada pela Zoologia pois os índios aprendem in loco quase que diariamente através da experiência concreta e da transmissão oral do conhecimento pelos homens e mulheres mais velhos das aldeias. Este contato estreito com os elementos naturais também permite, por exemplo, a descoberta de propriedades terapêticas de animais e plantas, não por acaso ou acidente, mas como resultado de várias experimentações ao longo de milhares de anos. Assim, os índios objetivam o conhecimento da natureza atravésda nomenclaturae taxonomias

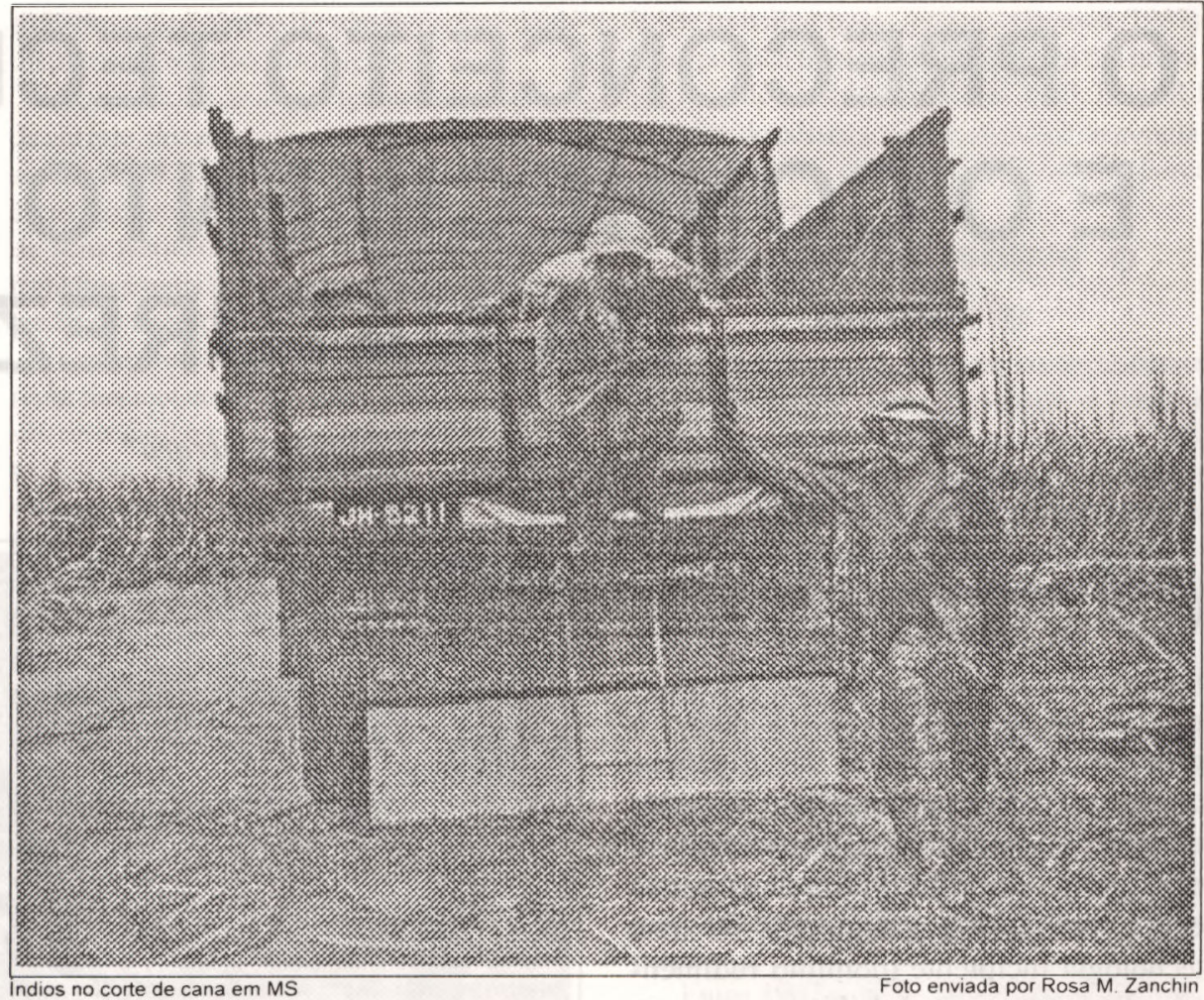

e as utilizam também para finalidades práticas. Embora a "ciência do concreto" indigena não seja função somente dos usos práticos dos elementos naturais pois o pensamento indigena (denominado mítico por Lévi-Strauss) se vale constantemente de tais ordenações da natureza, metaforizando e relacionando elementos sociais e naturais.

Esta racionalidade indigena ou pensamento mágico que está presente não somente nas populações indígenas, mas também no meio rural c urbano, opera principalmente com um combinação de elementos naturais e sociais. São as qualidades estéticas destes objetos da natureza e da sociedade (designadas especificamente por culturas detcrminadas) sobre as quais se baseia tal tipo de raciocínio. Um exemplo desta característica fundante da racionalidade mágica do pensamento indígena é o caso dos Xavante (população indigena distribuida $\mathrm{em}$ ilhas a sudeste de Mato Grosso). Estes utilizam determinadas raizes para curar a diarrćia com sangue, ou seja, as raizes de coloração avermelhada depois de cozidas resultam numa solução vermelho-sangue, uma das razões que justificam a sua utilização para curar este tipo de afecção.
Enfim, a estética que serve tanto aos princípios de classificação da natureza quanto aos usos determinados de plantas e animais pelos indígenas, é também uma base indireta de que se serve o pensamento cientifico ocidental. O último não está isento de verificar e testar hipóteses que na prática mágica (solução vermelho-sangue de raízes / diarréia com sangue) já estão confirmadas por associações não casuais ou fortuitas e de eficácia comprovada pois produtos de experimentações milenares.

Assim, a descoberta de um novo medicamento pela ciência ocidental deve se bascar nas experimentações e testes já elaborados pelos índios e pessoas do campo, os quais continuam a interagir diretamente com a natureza. O que não acontece nos laboratórios das faculdades, onde uma planta, por exemplo, só pode ter suas virtudes terapêuticas confirmadas através de análises químicas c experimentos com cobaias. Embora esta confirmação não invalide o conhecimento indigena ou popular, só justificando ou negando-o de uma outra maneira diferente do pensamento mágico.

Mas é bom que se diga, a "racionalidade" mágica ou "magia" não é um sinônimo de irracionalidade pois tem 
uma lógica própria para explicare solucionar os problemas apresentados pela interface entre o homem e a natureza. Isto é, a causalidade e substância de uma doença é tratada pelos índios de um jeito diferente da medicina ocidental. O que não quer dizer que os xamãs (curandeiros $\mathrm{e}$ líderes cerimoniais) scjam mais atrasados que os médicos pois tanto o xamã quanto o médico podem chegar a resultados satisfatórios ou não, onde os dois tipos de procedimento podem se tornar complementares.

A diferença entre o pensamento indígena (mítico) e o pensamento ocidental está nos resultados práticos a que podem chegar a ciência e, a racionalidade mágica. $\mathrm{O}$ que não quer dizer que o resultado prático de um conhecimento indígena não seja tão eficaz e, em alguns casos, até melhor que o utilizado pela tecnologia ocidental.

\section{O Bom Selvagem e a realidade indígena}

A figura do índio como "bom selvagem', que preserva e não destrói a floresta e os animais (o índio romantizado), faz parte do imaginário ocidental dos povos indígenas que vivem hoje no Brasil. Mas como todo ser humano o índio também transformou e ainda transforma o meio ambiente que o rodeia.

A extração do ouro, madeira e outras matérias-primas de grande valor, para as indústrias das sociedades modernas, em áreas indígenas só pode ser explicada por pressões exercidas por grupos empresariais (madeireiros, mineradoras, fazendeiros, etc.) que visam o lucro fácil através do modelo de economia extrativista. Este tipo de economia comumente não respeita os conhecimentos indígenas da natureza (acima mencionados) e, nem tampouco o manejo de florestas, campos agrícolas, animais e plantas que os índios estão acostumados a fazer durante séculos.

Embora existam alternativas ao modelo econômico extrativista, como o desenvolvimento auto-sustentado de comunidades indígenas (o qual visa potencializar os recursos naturais, renovando-os), a pressão de fazendeiros, empresários e políticos contra a demarcação efetiva das terras e autonomização dos povos indígenasé muito forte. Esta faz com que algumas tribos permitam a exploração (ou elas mesmo explorem) de madcira e outras matériasprimas, a fim de não perderem o controle econômico e político de suas terras

Qual seria a alternativa tecnológica (econômica), excluidoo modelo extrativista (sem renovação dos recursos naturais), para garantir territórios indígenas, dos quais dependem os índios para sobreviver física e culturalmente? Seria a aplicação de tccnologias agrícolas ou pastoris, a fim de adaptá-los forçosamente a um modelo de desenvolvimento agrícola ou pastoril? ou, o resgatc de conhecimentos indigenas dos ciclos ecológicos, das plantas, dos animais, enfim do mancjo do meio ambiente que realizam em suas terras muito antes do contato com os brancos e da onda ecológica estar em voga?

Antes de responder a esta questão (que de certa mancira se liga à primeira colocada no início deste artigo) ${ }^{1}$, é bom relembrar que a tecnologia por si só não determina a transformação social. Pois sua adoção ou mesmo acionamento depende de uma série de fatores que estruturam e operam em culturas indigenas. Só para citar alguns deles: a história própria de cada comunidade; o contato com outras populações; a relação mantida com o meio ambiente ao nível simbólico e prático (elementos indissociáveis); a economia indigena, envolvida com as relações de parentesco; as normas e relaçõcs sociais e; a polícia interna às aldeias $\mathrm{e}$ povos indigenas. Enfim, uma tecnologia estranha à prática e ao entendimento indígena não é adotada de imediato pelos índios, mas deve adaptar-se e por eles ser adaptada ao seu modo específico de organização cultural e social, o que inclui seus conhecimentos da natureza.

Desta maneira, forçar os índios a se adaptarem ao trabalho e manejo de novas técnicas e procedimentos agrícolas e pastoris, por exemplo, é no mínimo desrespeitar seus conhecimentos e hábitos culturais de como lidar com a terra, as plantas e os animais. É claro que os índios como cidadãos devem ter a liberdade de escolher entre um projeto ou outro para o desenvolvimento econômico de suas aldeias, a fim de fazer frente à cxpansão da sociedade envolvente. Não como resistência preocupada $\mathrm{em}$ conservar a cultura indígena num redoma de vidro, mas para tornar sua economia competitiva dentro de um mercado capitalista.

É necessário que haja uma assessoria aos povos indígenas neste nível econômico, como a dos profissionais em Antropologia, Biologia, Engenharia Florestal e Agronomia que trabalhem conjuntamentc. Pois a união dos conhecimentos e experiências destes com os saberes e necessidades econômicas e sociais dos índios seria 0 primeiro passo na tentativa de autonomizar cconomicamente as sociedades indígenas. Cabe lembrar que tal assessoria é mais um apoio do que uma força de determinação de escolha e modo de desenvolvimento do projeto de sustentação econômica, mesmo porque a última palavra sempre é dada pelos próprios índios.

Fica claro que o elemento tecnológico não pode ser tomado como único elemento classificador das sociedades pois a tecnologia se origina e se transforma através da sociedade e, não o contrário. Desta maneira, as alternativas tecnológicas das populações indígenas estão submetidas às suas diversas culturas, embora seja interessante que a tecnologia exterior ao conhecimento e prática indígenas valorize a "ciência do concreto"' indígena em benefício não só das economias indígenas, como da própria ciência ocidental e do futuro do próprio planeta.

* Eduardo Carrara é mestrando em Antropologia SocialUSP e Pesquisador em Etnologia Indigena junto à população Xavante - Reserva São Marcos/ $M T$

\section{NOTA}

(1) Por que as sociedades indigenas ("selvagens" e "bárbaras") não alcançaram o grau de desenvolvimento científico e tecnológico do Ocidente? Este que é um falso problema, como foi demonstrado anteriormente, ainda deixa em aberto a questão de como as sociedades indigenas (tão diferenciadas material e culturalmente do Ocidente) podem fazer frente ao avanço da sociedade moderna industrial.

\section{BIBLIOGRAFIA}

- BOAS, Franz. "The Mind of Primitive Man", New York, Macmillan, 1938.

DURKHEIM, Emile e MAUSS, Marcel. "Algumas Formas Primitivas de Classificação - Contribuição para o estudo das representaçōes coletivas. Săo Paulo, Ática, Col. Grandes Cientistas Sociais, 1955 - LÉVI-STRAUSS, Claude. "O Pensamento Selvagem", Campinas, SP, Papirus. 1989.

- MORGAN, Lewis H. "A Sociedade Primitiva", vol. 1 Portugal-Brasil, Presença, Martins Fontes.

- PFAFFENBERGER, Bryan. "Fetishised objects and Humanized Nature: Towards an Anthropology of Technology" In: Man (N.S.)23; 236-252.

-TYLOR, Edward. "Primitive Culture", várias ediçōes. 